\title{
Correlation between perimenopausal syndromes and depression in nurses at Sanglah General Hospital
}

Ni Wayan Dewi Putriny Asih, Ni Ketut Sri Diniari, Cokorda Bagus Jaya Lesmana, Luh Nyoman Alit Aryani, Anak Ayu Sri Wahyuni

Department of Psychiatry, Faculty of Medicine Udayana University/Sanglah General Hospital Bali, Indonesia
Cite this article:

Asih NWDP, Diniari NKS, Lesmana CBJ, Aryani LNA, Wahyuni AAS. Correlation Between Perimenopausal Syndromes and Depression in Nurses at Sanglah General Hospital. Journal of Clinical and Cultural Psychiatry. 2020; I(I): 14-17.

\section{Corresponding author:}

\section{Cokorda Bagus Jaya Lesmana}

Department of Psychiatry, Faculty of Medicine Udayana University/Sanglah General Hospital Jl. Kesehatan No I, Bali 80I I4, Indonesia cokordabagus@unud.ac.id

\begin{abstract}
Background: Perimenopause covers the period immediately before the menopause and the first year after the last menstrual period. In addition to the changes of the menstrual cycle, women in the perimenopause phase often report a number of perimenopausal complaints and depressive disorders. This study aims to determine the prevalence of perimenopausal complaints and depression experienced in nurses at Sanglah General Hospital.

Methods: The study uses a cross-sectional analytical. The measurement of perimenopause complaints uses the Menopause Rating Scale (MRS) questionnaire and the depression measurement uses the Beck Depression Inventory-II questionnaire (BDI-II). The data are analyzed descriptively, it uses the Fisher test and linear regression test with significance level $\mathrm{p}<0.05$.

Results: Nurses who have the perimenopausal complaints are $62.7 \%$. Besides, the depression is experienced by $23.8 \%$ of nurses who have perimenopausal complaints. The complained somatic symptoms with mild degree is $50 \%$ and moderate degree is $40 \%$. While the urogenital sexual symptoms with moderate degree is $60 \%$, and mild and severe degrees are $20 \%$.

Conclusion: This study shows the relationship between perimenopausal complaints and the depression of the nurses in Sanglah General Hospital. Therefore, it is necessary to held an early detection of depression prevention by screening perimenopausal complaints.
\end{abstract}

Keywords: perimenopause, depression, nurses, menopause rating scale

\section{Introduction}

Depression is a mood disorders characterized by sad feeling, lethargy, lack of passion for life, feeling of being useless, and despair. The prevalence of depression is very high, at least 35 million people in the world experience depression during their lives and $17 \%$ come to the practice of doctors with somatic complaints. ${ }^{1}$ A survey conducted by World Mental Health in 17 Countries found that 1 in 20 people had episodes of depression. In Indonesia, $11.6 \%$ of the adult population, namely around 1,740,000 people are depressed, and this number will increase often with increasing psychosocial pressure, chronic illness, diverse life and increasing age in this case related to the cycle menstruation. ${ }^{2}$ A woman goes through various stages of life from puberty, menstruation, pregnancy, to menopause, which cannot be separated from the role of the hormone estrogen that underlies emotional events and social changes occur. ${ }^{3}$ Menopause is the final stage of a woman's life cycle which is marked by the end of the cycle menstruation. Menopause is defined as a permanent cessation of menstruation for 12 months or more, and is usually experienced by middle-aged women. Some menopause complaints can interfere with daily activities. Unfortunately, most women are unaware of the changes in the menopause phase. In some women, com- 
plaints may even appear during the early perimenopause stage ${ }^{4}$ Perimenopause is a transition to menopause that begins before menopause occurs. The perimenopause phase has both physical and psychological effects on a woman. The psychological impact can be in the form of depressive symptoms such as excessive anxiety, paranoid, irritable and offended by trivial things, feeling herself is a burden, excessive sadness, depressed, and always thinking negatively to insomnia. ${ }^{5}$

Previous research has shown that there may be a relationship between perimenopausal complaints and depression or vice versa. This study was conducted to obtain the prevalence of perimenopausal complaints and depression and their relationship which can be useful for the prevention and early detection of depression in the perimenopause phase.

\section{Material and Methods}

This study is an observational analytic study with a cross-sectional design to determine perimenopause complaints in nurses at Sanglah Hospital and how they affect depression. This research was conducted at Sanglah Hospital from April to May 2019. The target population of the study were all female nurses at Sanglah Hospital.

The inclusion criteria include aged 45-55 years, had a clinical perimenopause phase, were willing to participate in the study by signing informed consent. Exclusion criteria were a history of gynecology that caused early menopause, a history of suffering from depressive disorders or previous psychiatric disorders, having a disease with menopausal symptoms (cancer, thyroid disease, autoimmune disease, heart disease). Data sources were collected directly from research subjects as primary data. Data collection was carried out using a questionnaire. Samples taken were 67 people who used simple random sampling method. This study was approved by the Ethics Committee of the Faculty of Medicine, Udayana University.

Each subject was asked to fill out 3 questionnaire sheets which consisted of filling in baseline data, Beck Depression Inventory II (BDI II) and Menopause Rating Scale (MRS). BDI II is used to obtain data on depressive symptoms and depressive symptoms in perimenopausal women. BDI II consists of fifteen questions consisting of depressive symptoms and the sample selects one of four choices of perceived conditions. BDI II Questionnaire has been used in various places in the world in the practice of psychiatry. A BDI II score of more than fourteen is considered to be diagnosed as depression.

MRS is a validated instrument for measuring the quality of life of menopausal women. Three dimensions of perimenopausal symptoms that were identified using the MRS questionnaire were: somato-vegetative, psychological, and urogenital. The MRS questionnaire consisted of 11 question items which included assessments of 3 perimenopausal complaint domains that were filled in by the respondent themselves. Assessments include somato-vegetative (hot flash, heart discomfort, palpitations, sleep problems and muscle and joint problems), psychological symptoms of depression (irritability, anxiety and physical and mental fatigue), and urogenital sexual problems (bladder problems and vaginal dryness). This study categorizes the somato-vegetative and sexual-urogenital subscales into no symptoms (score 0-2), mild symptoms (score 3-4), moderate symptoms (score $5-8)$ ) and severe symptoms (score $\geq 9$ ). The urogenital subscale is divided into no symptoms (score $0-2$ ), mild symptoms (score 1), moderate symptoms (score 2-3) and severe symptoms (score $\geq 4$ ).

The research data was recorded in a research sheet and processed with the help of a computer using Statistical Package for the Social Sciences (SPSS) 20th edition and displayed in tabular and narrative form. The comparative test uses the Chi Square test if it qualifies with the measurement scale of the catagoric variables of perimenopausal and depressive complaints data using a $2 \times 2$ crosstab table. If it does not meet the Chi Square test, an alternative test is used, the Fisher test.

\section{Result}

Based on the results obtained from questionnaires filled out by respondents namely female nurses aged 45-55 years in the scope of Sanglah Hospital, were obtained questionnaires that were filled with a total of 82 questionnaires. There were 15 respondents who were excluded from this study because they were in the postmenopausal phase as many as 10 people, had a history of thyroid cancer 1 person and a history of uterine disease as many as 4 people. The total respondents analyzed were 67 people who all met the inclusion criteria in this study. The basic characteristics of the sample can be seen in table 1.

Table 1. Basic characteristics of research subjects

\begin{tabular}{lcc}
\hline \multicolumn{1}{c}{ Variable } & Frequency & Percentage $(\%)$ \\
\hline Age (years), Mean \pm SD & $50.1 \pm 2.7$ & \\
Marital status & & \\
$\quad$ Married & 66 & 98.5 \\
Widow & 1 & 1.5 \\
Parity & 11 & \\
1 & 34 & 16.4 \\
2 & 22 & 50.7 \\
$\geq 3$ & & 32.8 \\
Ethnicity & 61 & \\
Balinese & 6 & 91 \\
Javanese & & 9 \\
Education & 1 & \\
Academy & 46 & 68.7 \\
Diploma & 19 & 28.4 \\
University & & \\
Menarche age & 2 & 3 \\
$\quad<12$ years & 55 & 82.1 \\
12-15 years & & 14.9 \\
$>15$ years & 10 & \\
\hline Contraception used & & \\
IUD & 47 & 70.1 \\
Pills & 2 & 3 \\
Tubectomy & 16 & 3 \\
None & & \\
\hline
\end{tabular}

Perimenopause complaints were experienced by 42 respondents (62.7\%) using the MRS questionnaire scoring with somatic symptom distribution of $41.7 \%$, psychological symptoms of $37.3 \%$, while urogenital symptoms of $67.2 \%$. Based on the severity, somatic symptoms obtained mild degrees of $31.3 \%$ and $10.4 \%$ moderate. Psychological symptoms obtained mild degree of $16.4 \%$, moderate degree of $17.9 \%$ and severe degree of $3 \%$. Urogenital symptoms with mild 
severity of $25.4 \%$, moderate severity of $29.9 \%$ and severe degree of $11.9 \%$. Depression was found in 10 respondents (14.9\%) among all study samples.

The results of this study found a prevalence of depression of $23.8 \%$ in respondents who had perimenopausal complaints. While respondents who are not depressed do not get complaints perimenopause. Among respondents who have perimenopausal complaints, a bivariate statistical test with catagoric variables is performed to see the relationship between perimenopausal complaints and depression. The results of the study obtained could not be done by Chi Square statistical tests because it did not meet the requirements that there are cells that have a value of 0 on the $2 \times 2$ crosstabs. The statistical test used is the alternative test, the Fisher test. Obtained Exact Sig value of 0.01 or $\mathrm{p}<0.05$, it can be concluded that statistically perimenopausal complaints have a relationship with the incidence of depression in female nurses who experience the perimenopause phase (Table 2). Perimenopausal complaints are one of the factors associated with depression.

Table 2. Distribution of depressive events based on perimenopausal complaints

\begin{tabular}{llccccc}
\hline & \multicolumn{5}{c}{$\begin{array}{c}\text { Perimenopause } \\
\text { complaints }\end{array}$} & \multirow{2}{*}{$\mathrm{P}$} \\
\cline { 2 - 6 } & & Yes & \multicolumn{3}{c}{ No } & \\
\hline Variable & $\mathrm{N}$ & $\%$ & $\mathrm{~N}$ & $\%$ & \\
\cline { 2 - 6 } $\begin{array}{l}\text { Depressive } \\
\text { state }\end{array}$ & Depressed & 10 & 23.8 & 0 & 0 & \multirow{2}{*}{$0.010^{\mathrm{a}}$} \\
\cline { 2 - 6 } & Not depressed & 32 & 76.2 & 25 & 100 & \\
\hline${ }^{a}$ Fisher's test & & & & &
\end{tabular}

\section{Discussion}

Perimenopause complaints arise as a result of hormonal fluctuations experienced during the perimenopause phase. The degree of perimenopausal complaints that arise varies between races. Population-based surveys say that Caucasians report more perimenopausal complaints than Asian. ${ }^{7}$ Hormonal fluctuations can occur without related changes in the menstrual cycle, so it is important to recognize that perimenopausal symptoms can precede the obvious changes in the menstrual cycle in middle-aged women. ${ }^{8}$

Social, cultural, psychological and environmental factors surrounding perimenopausal women also influence the appearance of perimenopausal complaints. Women with certain cultures have differences in behavior and complaints that arise. African women believe that the perimenopausal phase is the highest social level and will have an easier future. This helps African women to accept changes in the perimenopause phase more easily. Women in the USA, Germany and Italy consider the perimenopausal phase to be aging and become weak, so that their acceptance of the changes becomes more difficult. ${ }^{9}$

Most of the respondents in this study were from the Balinese ethnic group with 61 people (91\%) and Hindu people with 61 people (91\%). Balinese culture believes in 4 (four) levels of life called Catur Asrama which are expected to be a tiered order of human life. Most Balinese women in their 50s enter the Grahasta boarding stage. It was the most difficult time when he no longer only took care of himself but was burdened with taking care of his family. Emotional stability is very tested at this time. The prevalence of perimenopausal complaints in this study may be influenced by these cultural factors where the perimenopause phase is considered a difficult time.

The prevalence of depression is increasing in the SWAN study in the perimenopause phase which is $16.5 \%$. This may be caused by several things: a decrease in estrogen levels in the perimenopausal phase where estrogen affects neurotransmitters that control mood, depressive disorders caused by vasomotor syndrome, and depression that is influenced by psychosocial changes that are mostly experienced by perimenopausal women. Some psychosocial stressors experienced by perimenopausal women include: problems in marriage, children who have grown up, caring for parents, work responsibilities and myths associated with aging. ${ }^{10}$

The prevalence of depression in nurses who had perimenopausal complaints in this study was $23.8 \%$. Research conducted by Ruixia et al in China found a nearly equal prevalence rate of $25.99 \%$ with risk factors for age, work status, personality traits and age of menarche. ${ }^{11}$ Research by Ju-Yu Yen et al in Taiwan says that there is a relationship between depression and perimenopause complaints experienced. Studies conducted by Cohen et al. Show that the risk of depression in the perimenopausal phase increases with the appearance of vasomotor symptoms and changes in life events. If perimenopausal women experience both of these things, the tendency to experience depression will increase with an odds ratio of $2.5 .^{12}$

\section{Conclusion}

This study found that the prevalence of depression among nurses at Sanglah Hospital who had perimenopausal complaints was $14.9 \%$ and there was a significant relationship between perimenopausal complaints and depression.

\section{Acknowledgement}

The authors report no conflict of interests.

\section{Reference}

1. WHO. Depression in mentl health.2016.Available: http://psycnet.apa.org/record/1996-00434-003. Accessed 21 February 2019.

2. Kementrian Kesehatan. Depkes. 2013. Available: http://www. depkes.go.id/resources/download/general/hasil\%2520Riskesdas\%252 02013.pdf. Accessed 21 February 2019.

3. E. Purwoastuti.Apakah yang terjadi pada saat menopause? Menopause, siapa takut?.Yogyakarta.Penerbit Kanisius.2012. pp. 12-16.

4. E. Fidel. Perimenopausal and Postmenopausal Complaints in Paramedics Assesed by Menopause Rating Scale in Indonesia. Journal of Dental and Medical Sciences.2014;13(12):38-42.

5. B. Jagtap, B. Prasad and S. Chaudhury.Psychiatric morbidity in perimenopausal women. Industrial Psychiatry Journal. 2016;25(1):86 
6. A. Kusumawardani.Bagaimana tanda-tanda dan gejala depresi pada Perimenopause?.Depresi Perimenopause. Jakarta: FK UI, 2006:1-30.

7. N. Chuni and C. Sreeramareddy. Frequency of symptoms, determinants of severe symptoms, validity of and cut-off score for Menopause Rating Scale ( MRS ) as a screening tool : A cross-sectional survey among midlife Nepalese women. 2011.

8. A. Clayton and P. Ninan. Depression or Menopause? Presentation and Management of Major Depressive Disorder in Perimenopausal and Postmenopausal Women. Prim Care Companion J Clin Psychiatry. 2010:12(1).

9. R. Samouei and M. Valiani. Psychological experiences of wom- en regarding menopause. International Journal of Educational and Psychological Researches.2016.

10. Z. Gibbs, S. Lee and J. Kulkarni. What factors determine whether a woman becomes depressed during the perimenopause?. Archives of Women's Mental Health. 2012;15(5):323-332.

11. R. Li. Perimenopausal syndrome and mood disorders in perimenopause: prevalence, severity, relationships, and risk factors. Medicine. 2016;95:12-14.

12. R. Muharam, W. M. Setiawan, M. Ikhsan, et al. Depression and its link to other symptoms in menopausal transition. Middle East Fertility Society Journal.2018:0-3. 